\title{
Isolamento solidário em tempos de pandemia: diálogos entre a saúde e a hermenêutica filosófica
}

\author{
Solidary isolation in pandemic period: dialogues between health and philosophical \\ hermeneutics
}

\section{Gustavo Silvano Batista*, Fábio Solon Tajra**}

Resumo: A covid-19 tem gerado grande mobilização por parte das sociedades contemporâneas. Como forma de prevenção e controle da doença, o isolamento social tem sido uma medida eficaz, recomendada por diversos órgãos da saúde. Por isso, pensar o isolamento social como prática solidária tem sido fundamental. Nesta perspectiva, o presente artigo busca problematizar o isolamento social enquanto isolamento solidário. Para isso, partimos da tematização da enfermidade, até agora conhecida, seus modos de prevenção e controle e, por conseguinte, o diálogo entre a Saúde Coletiva e a Hermenêutica Filosófica, na tentativa de repensar o isolamento criticamente, para além de uma questão biomédica. Assim, discutir o isolamento solidário como noção essencial ao enfrentamento da pandemia da COVID-19 significa contribuir para uma vișão mais ampla de saúde, ao passo que se encontra em jogo o restabelecimento da vida comunitária para além de sua concepcão biomédica.

Palavras-chave: Pandemia; Saúde; Hermenêutica; Saúde Coletiva; Solidariedade

Abstract: Covid-19 has generated intense mobilization by contemporary societies. Social isolation has been adopted as an effective measure, recommended by several health agencies, for the prevention and control of the disease. Therefore, thinking the social isolation as a solidarity practice has been fundamental. In this perspective, the objective of this study is to problematize social isolation as solidarity isolation. For that, we start from the thematization of the disease, hitherto known, its modes of prevention and control and the dialogue between Public Health and Philosophical Hermeneutics, to critically rethink isolation, beyond a biomedical notion. Thus, discussing solidarity isolation as a fundamental notion in coping with the pandemic of COVID-19 means contributing to a broader vision of health, while the restoration of community life beyond its biomedical conception is at stake.

Keywords: Pandemics; Health; Hermeneutics; Public Health; Solidarity

\section{Situando a pandemia como questão biomédica}

A enfermidade causada pelo novo coronavírus ( $S A R S-C o V-2)$, popularmente tratada por COVID-19 (corona virus desease), teve seus primeiros casos divulgados inicialmente em Wuhan, China, no final de 2019, gerando grande mobilização social. Constitui uma doença infecciosa de rápida disseminação entre os países do mundo e tem atingido grande número de pessoas, com uma taxa de letalidade ainda imprecisa1,2,3,4,5. De acordo com a Organização

\footnotetext{
1 BELINGHERI, M.; PALADINO, M.E.; RIVA, M.A. COVID-19: Health prevention and control in non-healthcare settings.

2 FREITAS, A.R.R.; NAPIMOGA, M.; DONALISIO, M.R. Análise da gravidade da pandemia de Covid-19.

3 ZHONGHUA LIU, XING BING, XUE ZA ZHI. An update on the epidemiological characteristics of novel coronavirus pneumonia (COVID-19).

${ }^{4}$ ARAUJO-FILHO, J.A.B. et al. Pneumonia por COVID-19: qual o papel da imagem no diagnóstico?

5 SILVA, A.A.M. Sobre a possibilidade de interrupção da epidemia pelo coronavírus (COVID-19) com base nas melhores evidências científicas disponíveis.
}

\footnotetext{
* Professor do Departamento de Filosofia, Universidade Federal do Piauí, Teresina, PI. E-mail: gustavosilvano@ufpi.edu.br ORCID: https://orcid.org/0000-0002-9399-2541

** Docente do Departamento de Medicina Comunitária, Universidade Federal do Piauí, Teresina, PI. E-mail: fstajra@hotmail.com ORCID: https://orcid.org/0000-0001-7236-5541
} 
Mundial da Saúde (OMS), em 30 de abril de 2020, o número de casos confirmados de COVID19 já ultrapassava a marca de 3.059.642 e o número de mortes era de 211.028. No Brasil, foram registrados 71.886 casos confirmados da doença e 5.017 mortes, considerando o mesmo período 6 .

É importante mencionar que o número de casos confirmados faz referência àquelas pessoas que apresentaram sinais e sintomas da doença e realizaram o exame para confirmação do quadro clínico. Podem, ainda, ter sido reconhecidas a partir das testagens em massa que alguns países têm adotado. Contudo, é possível que uma grande parcela da população não tenha apresentado sintomatologia, não precisou de assistência médica e não foi submetida a nenhum tipo de testagem. Esses não integram tal lista, porque podem não ter sido notificados. Possivelmente, foram tratados no domicílio ou passaram despercebidos pela população. Mesmo assim, podem ter disseminado a doença sem mesmo saber que estava com o vírus.

Esse número elevado de casos pode colocar em colapso o sistema de saúde do país, uma vez que são necessárias medidas de enfrentamento que incluem a suplementação e oxigênio, a utilização de respiradores mecânicos e a internação em Unidades de Terapia Intensiva (UTI) nos casos de maior gravidade e de insuficiência respiratória7. É importante frisar que a assistência à saúde de pessoas que vivenciam COVID-19 exige o recrutamento de uma equipe multiprofissional imersos em uma prática interdisciplinar e intersetorial. Isso demanda para o gestor em saúde maior ênfase na organização e funcionamento dos serviços em rede.

A escassez de evidências sobre a doença tencionou para a realização de estudos e desenvolvimento de estratégias com a finalidade de vigilância, prevenção e controle. Algumas organizações internacionais e nacionais têm sugerido a aplicação do plano de contingência de influenza, devido às semelhanças clínicas e epidemiológicas com aquele vírus ${ }^{8,9}$. Esse plano leva em consideração o número reprodutivo básico (R0) que estima a velocidade com que uma doença se propaga na população. Quando o número médio de casos secundários, causado por um único agente infeccioso numa população totalmente susceptível, for superior a um, pode ocorrer um quadro de epidemia. Ao ameaçar muitas pessoas ao redor do mundo simultaneamente, temos uma pandemia ${ }^{10}$. É isso que está acontecendo com a COVID-19.

Diante desse panorama epidemiológico, uma das medidas consideradas eficazes para a diminuição da propagação do vírus tem sido o isolamento social. Essa estratégia está alicerçada na redução do número de contatos entre as pessoas, independente da manifestação ou não dos sintomas ${ }^{11,12,13,14,15}$. Esse isolamento também visa a proteção dos profissionais de saúde que atuam na área, assim como o controle sobre a utilização dos serviços de saúde. Pensando nisso, diversos movimentos têm sido realizados por parte da sociedade civil e

\footnotetext{
6 WORLD HEALTH ORGANIZATION. Coronavirus disease (COVID-19) outbreak.

${ }^{7}$ CONSELHO REGIONAL DE FARMACIA DO ESTADO DE SÃO PAULO. Departamento de Apoio Técnico e Educação Permanente. Manual de Orientação ao Farmacêutico: COVID-19.

8 BELINGHERI, M.; PALADINO, M.E.; RIVA, M.A. COVID-19: Health prevention and control in non-healthcare settings.

${ }_{9}^{9}$ FREITAS, A.R.R.; NAPIMOGA, M.; DONALISIO, M.R. Análise da gravidade da pandemia de Covid-19.

10 MAGALHAES, S.S.A.; MACHADO, C.J. Conceitos epidemiológicos e as pandemias recentes: novos desafios.

${ }^{11}$ HELLEWELL, J.; ABBOTT, S.; GIMMA, A.; BOSSE, N.I.; JARVIS, C.I.; RUSSELL, T.W., et al. Feasibility of controlling COVID-19 outbreaks by isolation of cases and contacts.

12 WORLD HEALTH ORGANIZATION. Report of the WHO-China Joint Mission on Coronavirus Disease 2019 (COVID19).

13 SILVA, A.A.M. Sobre a possibilidade de interrupção da epidemia pelo coronavírus (COVID-19) com base nas melhores evidências científicas disponíveis.

${ }^{14}$ FARIAS, H.S. O avanço da Covid-19 e o isolamento social como estratégia para redução da vulnerabilidade.

15 SAMPAIO, L.R.; CAMINO, C.P.S.; ROAZZI, A. Revisão de aspectos conceituais, teóricos e metodológicos da empatia.
} 
governos municipais e estaduais como, por exemplo, "Nós estamos aqui por vocês. Fique em casa por nós", que busca mobilizar os indivíduos acerca do controle da doença por meio de uma prática comum.

Nesse sentido, considerar o isolamento social como uma prática solidária tem sido um desafio para a construção do diálogo entre a saúde coletiva e a hermenêutica filosófica. Tratase de uma reflexão importante ao reconsiderar o momento que a sociedade global tem enfrentado. Nesse sentido, o presente artigo tem como objetivo analisar o isolamento social na perspectiva da conceitualização hermenêutica da solidariedade, noção-chave do pensamento de Gadamer e condição própria da vida comunitária a ser ainda ressignificada. Busca-se repensar o isolamento social enquanto isolamento solidário como uma contribuição da hermenêutica filosófica à saúde coletiva, visando problematizar o sentido do isolamento e refletir acerca do seu caráter prático, justificando a eficácia da prevenção e controle da COVID-19 que, por conseguinte, reorienta a vida em comum.

\section{O isolamento social como estratégia da Saúde Coletiva}

Grandes epidemias assolaram as diversas nações no passado. Algumas delas foram responsáveis pela dizimação da população de algumas cidades e regiões e mudaram o curso da história humana ${ }^{16}$. Há pouco mais de cem anos, a Gripe Espanhola, detectada inicialmente no Kansas - Estados Unidos, foi responsável por milhões de óbitos. Os registros apresentam uma variação entre 20 a 50 milhões de óbitos no mundo inteiro. Essa pandemia pode ter sido agravada em virtude do contexto pós-guerra vivenciado naquela oportunidade que provocou uma série de vulnerabilidades à população mundial, dentre elas, o acesso limitado de alimentos, assim como fatores socioeconômicos ligados ao empobrecimento e condições de vida das populações ${ }^{17}$.

Aquela pandemia foi causada pelo vírus da Influenza A (H1N1) que é passível de mudança no material genético. Isso se reflete na diversificação do vírus que pode acontecer de forma mais expressiva (shift antigênico), dando origem a um novo subtipo de vírus. Esse fato desafia o sistema imune animal e explica a necessidade de atualização periódica da vacina ${ }^{18}$. Um quadro parecido aconteceu em 2009, quando uma nova pandemia relacionada à variação do material genético da Influenza assolou os cinco continentes. Nesse caso, foi menos expressiva que a anterior.

Essas experiências anteriores possibilitaram a definição de alguns aspectos essenciais para evitar uma nova tragédia, a saber: o aprimoramento da vigilância epidemiológica, responsável pela produção das informações que poderão subsidiar a recomendação e adoção de medidas de prevenção e controle das doenças ou agravos; a pesquisa clínica que permite o sequenciamento do vírus; e, por último, a estrutura laboratorial voltada à formação de novos insumos e biológicos que inclui a produção de vacinas e medicamentos ${ }^{19}$.

É importante mencionar que estas ações técnicas, próprias da área da saúde, devem estar ancoradas em uma proposta prático-política, que deverá oferecer condições básicas para que essas ações possam ser devidamente materializadas. Além do financiamento para fins científicos e de desenvolvimento de tecnologias, é indispensável o desenvolvimento do potencial humano capaz de lidar com a situação.

\footnotetext{
${ }^{16}$ REZENDE, J.M. À sombra do plátano: crônicas de história da medicina.

${ }^{17}$ MATOS, H.J. A próxima pandemia: estamos preparados?

${ }^{18}$ CINTRA, O.A. L.; REY, L.C. Segurança, imunogenicidade e eficácia da vacina contra o vírus influenza em crianças. ${ }^{19}$ MATOS, H.J. A próxima pandemia: estamos preparados?
} 
Ao pensar nisso, é importante explorar uma questão prática que depende da experiência de cidadania e relaciona a promoção da vida em comunidade, sem perder de vista o próprio cuidado de si. Tal concepção de cidadania, basicamente alinhada ao projeto hermenêutico de Gadamer, indica um acontecer compreensivo próprio das ações de saúde, ou seja, tem-se sempre presente a ideia de participação, atuação e ação com a finalidade de construir um destino próprio. Contudo, ao longo dos tempos, constatamos diferentes graus e formas de participação dos indivíduos, bem como sua abrangência social ${ }^{20}$.

De fato, a COVID-19 oportunizou mais um momento de crise civilizacional e, por conseguinte, proporcionou uma reflexão sobre nossa condição diante da vida e da morte. Gerou um debate decisivo sobre a importância da adoção de estratégias em defesa da vida, assim como nossa participação e atuação diante das demandas da condição atual. Nesta perspectiva, há uma aproximação fundamental entre o exercício das atividades de saúde e o exercício da cidadania, ambas marcadas pelo engajamento a favor da vida de cada indivíduo e, por conseguinte, da própria comunidade.

0 isolamento social tem sido uma das estratégias mais eficazes para a efetividade do cuidado em saúde. É uma medida exigente e individualizada da ordem da solidariedade para exercício do cuidar-de-si e do cuidar-do-outro nos moldes de um comprometimento responsável consigo e com os outros.

Alguns estudos mencionam uma taxa de sucesso do isolamento em torno de $80 \%$. Esse valor foi obtido a partir de um modelo matemático que utilizou como referência o número de casos iniciais, o número básico de reprodução (R0), o atraso do início dos sintomas para o isolamento, a probabilidade de rastreamento dos contatos, a proporção de transmissão que ocorreu antes do início dos sintomas e a proporção de subclínicos. Na maioria dos cenários, essa estratégia apresentou excelentes resultados para o controle um novo surto no prazo de três meses $21,22,23,24$.

Isolar-se tem sido basilar na prevenção e controle da COVID-19. É o desafio do exercício de lidar com uma realidade social que requer envolvimento e empatia em prol de uma situação comum. Aqui, o isolamento pode ser pensado como uma experiência que reivindica uma estruturação coletiva e horizontal. É alicerçado a partir de múltiplas dimensões técnicas e sociais e leva em consideração os níveis de afetações oportunizadas aos sujeitos. Essas afetações rompem com a perspectiva individual e tencionam para o desenvolvimento do olhar sobre sua própria condição, sua participação em uma comunidade, cujas ações ressoam sobre os outros e oportunizam efeitos ${ }^{25}$.

A compreensão do isolamento social como uma medida comum salutar possibilita a construção de novos vínculos e, por conseguinte, o fortalecimento daqueles já existentes. Aliado a isso, oportuniza uma nova forma de lidar com o outro e o mundo ao seu redor. Para a sua manutenção, foram desenvolvidas estratégias intermediadas por tecnologias de comunicação e informação. Além da produção de conteúdo, foram disponibilizados serviços e meios de comunicação digital. Dessa forma, o desenvolvimento de aplicativos, de serviços de entrega em domicílio, o trabalho remoto, a utilização das videoconferências e videochamadas, a veiculação de debates com especialistas e de apresentações artísticas foram alternativas

\footnotetext{
${ }^{20}$ RIBEIRO, L.C.Q. Cidade e cidadania: inclusão urbana e justiça social.

${ }^{21}$ HELLEWELL, J.; ABBOTT, S.; GIMMA, A.; BOSSE, N.I.; JARVIS, C.I.; RUSSELL, T.W., et al. Feasibility of controlling COVID-19 outbreaks by isolation of cases and contacts.

22 WORLD HEALTH ORGANIZATION. Coronavirus disease (COVID-19) outbreak.

23 SILVA, A.A.M. Sobre a possibilidade de interrupção da epidemia pelo coronavírus (COVID-19) com base nas melhores evidências científicas disponíveis.

${ }^{24}$ FARIAS, H.S. O avanço da Covid-19 e o isolamento social como estratégia para redução da vulnerabilidade.

${ }_{25}$ SAMPAIO, L.R.; CAMINO, C.P.S.; ROAZZI, A. Revisão de aspectos conceituais, teóricos e metodológicos da empatia.
} 
para esse novo contexto e cenário social. Ainda assim, será oportuno o desenvolvimento de estudos para avaliar a saúde em todos os seus aspectos, incluindo a saúde mental.

\section{0 isolamento social na perspectiva da hermenêutica da saúde: o isolamento solidário}

Refletir, a partir das contribuições filosóficas de Gadamer, sobre o sentido do isolamento social significa discutir tal assunto inserido em um horizonte mais amplo no qual estamos basicamente envolvidos: o âmbito da vida prática enquanto ambiente de promoção e manutenção da saúde. Como Gadamer afirma em diversos momentos de sua obra, tal âmbito encontra-se fundamentalmente remodelado pela ciência e, por conseguinte, pelo impacto da tecnologia. Para Gadamer, "vivemos em um meio ambiente cada vez mais transformado pela ciência, um meio o qual quase já não ousamos mais chamar de natureza, ao mesmo tempo que temos de viver em uma sociedade modelada pela cultura cientifica da era moderna" 26 . Um dos principais sintomas dessa configuração histórica é o modo de vida no qual estamos inseridos, especialmente como lidamos com a promoção da vida, o que significa questionar e repensar a noção comum de saúde e, por conseguinte, que tipo de saúde é verdadeiramente promovida.

Nessa perspectiva, a pandemia da COVID-19 surgiu como um momento no qual a vida prática em comunidade é novamente repensada em todos os seus níveis, especialmente no âmbito da relação com os outros e no modo como se lida com o cenário já posto. Em se tratando de um evento pandêmico e, por isso, diretamente relacionado a saúde coletiva, é importante ressaltar, na perspectiva de Gadamer, a influência efetiva do próprio modo como a vida é pensada pela área biomédica. Conforme afirma Gadamer,

Nós nunca podemos nos livrar completamente do fato de que a nossa experiência científica e médica está voltada, primeiramente, a uma subjugação do aparecimento da doença. Trata-se, por assim dizer, de uma subjugação da natureza, ali onde a doença se manifesta. 0 importante é que se domine a doença ${ }^{27}$.

Como apontado por Gadamer, há uma cultura biomédica, ainda atuante, que dá ênfase à enfermidade. Esse entendimento, pressupõe atenção ao domínio das situações de dano, percebendo a saúde essencialmente como ausência de doenças. Isso justificaria a necessidade de combater as doenças a partir de diferentes estratégias, desde pesquisas científicas até terapias medicamentosas que possam aniquilá-las e, assim, recompor a condição de saúde e bem-estar. Como nos lembra Ayres,

A conceituação biomédica da doença pode ser caracterizada, sinteticamente, por um conjunto de juízos de caráter instrumental, orientados normativamente pela noção de controle técnico do obstáculos naturais e sociais a interesses práticos de indivíduos e coletividades, tendo como base material o conhecimento e domínio de regularidades causais no organismo (corpo/mente/meio) e, como forma de validação, uma série bem definida de critérios a priori para o controle das incertezas ${ }^{28}$.

Tal visão, que pressupõe uma visão estritamente científica da vida humana, ajuda-nos a compreender o isolamento social como uma medida técnico-científica, no intuito de evitar a disseminação da doença e, por conseguinte, a prevenção e o controle dessa enfermidade. Contudo, nesse argumento reside um desafio elementar para as áreas de saúde e hermenêutica: compreender o que a saúde efetivamente é, tendo em vista o horizonte básico

26 GADAMER, 0 caráter oculto da saúde, p. 110.

27 GADAMER, O caráter oculto da saúde, p. 111.

${ }^{28}$ AYRES, J.R. Uma concepção hermenêutica de saúde, p. 46. 
da vida prática. Por essa razão, deve-se ir além da promessa preventiva. É preciso estar atento ao acontecimento que é a própria saúde, superando o caráter absoluto da visão científica da saúde, compreendendo-a de modo mais amplo, ou seja, inserida na esfera da vida enquanto um evento de efetividade histórica de reencontro com a vida e seu processar. Diz Gadamer:

A saúde depende de muitos fatores e, no final, encontra-se não somente a saúde, mas a reintrodução do paciente na sua antiga posição na vida cotidiana. Somente isso é a plena recuperação (Wiederherstellung), que, com certeza, frequentemente ultrapassa as possibilidades e competências do médico ${ }^{29}$.

Assim, partindo da visão hermenêutica da saúde, para além da ausência de doenças, nos termos da reinserção dos indivíduos na vida em comunidade, especialmente na situação de pandemia, é importante refletir sobre um novo sentido para o isolamento social que, entre outras medidas já elencadas ao decorrer deste texto, tem-se mostrado especialmente eficaz tanto na prevenção e controle da doença quanto no questionamento acerca da própria vida em comunidade enquanto desejo de retorno a vida cotidiana. Nesse sentido, como diz Ayres,

A experiência da saúde envolve a construção compartilhada de nossas ideias de bem-viver e de um modo conveniente de buscar realizá-las na nossa vida em comum. Trata-se, assim, não de construir objetos/objetividade, mas de configurar sujeitos/intersubjetividades ${ }^{30}$.

Dessa forma, pensar o isolamento social em termos hermenêuticos, é ressignificá-lo em sua relação com a esfera da vida efetiva em comunidade, ou seja, é buscar seu sentido de forma mais ampliada, tendo em vista não somente a resistência à contaminação individual, mas ainda promover a vida comunitária, ainda que pareça se resumir a um momento de confinamento nos moldes da quarentena médica.

Uma concepção hermenêutica de saúde requer, notadamente no momento de pandemia, não somente o cumprimento do isolamento social, mas a compreensão de seu sentido, tendo em vista a vida com os outros. É decisivo inserir uma medida de isolamento em um horizonte mais amplo de convivência, mesmo modificada pela situação comum, pensandoa como um período momentâneo de revisão da vida. Nesse sentido, Gadamer compreende a vida com os outros em comunidade por meio de uma consciência comum que reúne a todos como um elo, sempre que surge um novo desafio global comum. Esse elo é a solidariedade. Como afirma Gadamer,

Estamos ainda muito distantes de ter alcançado uma consciência comum - no sentido de que o que está em jogo é o destino de todos sobre a terra em que ninguém pode sobreviver, à semelhança do que acontece com a insensata utilização de armas de destruição atômica - já que a humanidade, ao longo de, talvez, muitas e muitas crises e muitas experiências dolorosas não consegue encontrar - por necessidade - uma nova solidariedade ${ }^{31}$.

A necessidade da adoção de novas medidas torna-se um caminho através do qual poderíamos ainda pensar o sentido do isolamento, ou seja, o seu caráter solidário. Por isso, refletir sobre o isolamento solidário significa, em um primeiro momento, considerar uma atitude que nos reúne no enfrentamento de um problema comum - a pandemia - o que possibilita a promoção de uma consciência comum. Tal aspecto indica uma iniciativa que deve ser disseminada para além do aparato biomédico da saúde, ou seja, trata-se de uma prática que depende do engajamento de todos e cada um a favor da vida comum.

${ }^{29}$ GADAMER, 0 caráter oculto da saúde, p. 134-135.

${ }^{30}$ AYRES, J. R. Uma concepção hermenêutica de saúde, p. 50.

31 GADAMER, A razão na época da ciência, p. 55. 
Em um segundo momento, podemos entender o isolamento solidário como uma ação de cuidado consigo mesmo e com os outros, tendo em vista, em um momento por vir, a retomada da vida em comunidade, ou seja, a reintegração no processar da vida cotidiana. Gadamer compreende situações-chave que nos reúnem, tal qual o isolamento solidário, como um momento de despertar para novas solidariedades, ou seja, novas possibilidades de pensar a saúde coletiva, para além de suas preocupações técnico-científicas, em busca de uma vida em comum equilibrada. É por essa via que, segundo Gadamer, é possível a promoção da práxis da vida em comum enquanto um ambiente de promoção de saúde e não somente de irradicação de enfermidades. Nas palavras de Gadamer, "a solidariedade é a condição decisiva e a base de toda razão social ${ }^{32 "}$.

Assim, tendo em vista o momento de pandemia no qual diversas atitudes da saúde, tais como a vigilância epidemiológica, a pesquisa científico-clínica e a estruturação dos equipamentos de saúde e laboratórios são fundamentais para o enfrentamento da enfermidade, também se coloca como fundamental a recuperação de uma experiência solidária nos termos do isolamento. Desse modo, repensar o isolamento, considerando-o não mais como um modo de afastamento do convívio da vida, mas, ao contrário, como uma medida que tem em vista a relação saudável com o outro.

Mesmo parecendo contraditório aproximar isolamento e solidariedade, inspirados nas reflexões de Gadamer, poderíamos repensar tal relação enquanto uma noção - isolamento solidário - que ressignifica eficazmente a própria saúde e, em última instância, as relações humanas no processar da própria vida prática. Tal contribuição indica algo a ser examinado não somente pela filosofia hermenêutica e humanidades, mas também pelas áreas que compõe a saúde, especialmente a saúde coletiva.

Mesmo lidando com uma calamidade pública, com tantos efeitos negativos, especialmente a grande quantidade de vidas humanas irreparavelmente perdidas, 0 isolamento tem sido visto por muitos como uma medida ineficaz. Diversas vozes de líderes políticos e religiosos não têm compreendido o isolamento como um momento de solidariedade com os outros, como uma possibilidade de renovação da vida atual em outros termos, para além da instrumentalização do outro. Por isso, o sentido solidário do isolamento não poderia ser mais relevante, diante desse atual impasse, especialmente nas tentativas de romper o isolamento social em momentos indevidos.

Por fim, recuperar a experiência solidária do isolamento aparece como uma oportunidade de reexaminar a vida social, mesmo nesse momento grave de pandemia, à medida que possibilita não somente o vislumbramento de um retorno futuro ao curso renovado da vida prática efetiva, mas também na compreensão da saúde para além de um fato biológico, ou seja, como um fato comunitário-social no qual estamos inseridos basicamente como comunidade.

\section{Referências}

ARAUJO-FILHO, J.A.B. et al. Pneumonia por COVID-19: qual o papel da imagem no diagnóstico? Jornal Brasileiro de Pneumatologia, São Paulo, v. 46, n. 2, e20200114, 2020. Disponível em: https://www.scielo.br/pdf/jbpneu/v46n2/pt 1806-3713-jbpneu-46-02-e20200114.pdf. Acesso em: 08 de abril de 2020.

AYRES, J.R.C.M. Cuidado: trabalho, interação e saber nas práticas de saúde. Revista Baiana de Enfermagem, Salvador, v. 31, p. 3-4, 2017.

32 GADAMER, A razão na época da ciência, p. 56. 
AYRES, J.R.C.M. Hermeneutics, nursing and a pedagogy of the encounter. Nursing Philosophy, v. 20, p. 1-3, 2019.

AYRES, J.R. Para comprender el sentido práctico de las acciones de salud: contribuciones de la Hermenéutica Filosófica. Salud Colectiva, Buenos Aires, v. 4, p. 159-172, 2008.

AYRES, J.R. Uma concepção hermenêutica de saúde. Physis, Rio de Janeiro, v. 17, p. 43-62, 2007.

BELINGHERI, M.; PALADINO, M.E.; RIVA, M.A. COVID-19: Health prevention and control in non-healthcare settings. Occupational Medicine, Volume 70, Issue 2, March 2020, Pages 82-83.

CINTRA, O.A. L.; REY, L.C. Segurança, imunogenicidade e eficácia da vacina contra o vírus influenza em crianças. Jornal de Pediatria, Porto Alegre, v. 82, n. 3, supl. p. s83-s90, July 2006.

CONSELHO REGIONAL DE FARMÁCIA DO ESTADO DE SÃO PAULO. Manual de Orientação ao Farmacêutico: COVID-19. / Conselho Regional de Farmácia do Estado de São Paulo. São Paulo: Conselho Regional de Farmácia do Estado de São Paulo, 2020.

FARIAS, H. S. 0 avanço da Covid-19 e o isolamento social como estratégia para redução da vulnerabilidade. Espaço e Economia - Revista Brasileira de Geografia Econômica, n.17, 2020, Disponível em: https://journals.openedition.org/espacoeconomia/11357. Acesso em: 21 de abril de 2020.

FREITAS, A.R.R.; NAPIMOGA, M.; DONALISIO, M.R. Análise da gravidade da pandemia de Covid-19. Epidemiologia e Serviços de Saúde, Brasília, Vol. 29, n. 2, p. 1-5,2020. Disponível em: https://www.scielo.br/pdf/ress/v29n2/2237-9622-ress-29-02-e2020119.pdf. Acesso em: 23 de abril de 2020.

GADAMER, H.G. A razão na época da ciência. Rio de Janeiro: Tempo Brasileiro, 1983.

GADAMER, H.G. O caráter oculto da saúde. Petrópolis: Vozes, 2006.

HELLEWELL, J.; ABBOTT, S.; GIMMA, A.; BOSSE, N.I.; JARVIS, C.I.; RUSSELL, T.W., et al. Feasibility of controlling COVID-19 outbreaks by isolation of cases and contacts. Lancet Glob Health, London, n.8, 2020. Disponível em: https://doi.org/10.1016/S2214-109X(20)30074-7. Acesso em: 24 de abril de 2020.

MAGALHAES, S.S.A.; MACHADO, C.J. Conceitos epidemiológicos e as pandemias recentes: novos desafios. Cadernos de Saúde Coletiva, Rio de Janeiro, v. 22, n. 1, p. 109-110, 2014.

MATOS, H.J. A próxima pandemia: estamos preparados? Revista Pan-Amazônica de Saúde, Ananindeua, v. 9, n. 3, p. 9-11, set. 2018. Disponível em http://scielo.iec.gov.br/pdf/rpas/v9n3/2176-6223-rpas-9-03-9.pdf. Acesso em: 20 abr. 2020.

REZENDE, J.M. À sombra do plátano: crônicas de história da medicina. São Paulo: Editora Unifesp, 2009.

REIMÃO, Sofia. A questão da medicina e a morte como questão. Lisboa: Universidade Católica Editora, 2010.

RIBEIRO, L.C.Q. Cidade e cidadania: inclusão urbana e justiça social. Ciência e Cultura, São Paulo, vol.56 no.2, p. 43-45, 2004.

SAMPAIO, L.R.; CAMINO, C.P.S.; ROAZZI, A. Revisão de aspectos conceituais, teóricos e metodológicos da empatia. Psicologia: ciência e profissão, Brasília, v. 29, n. 2, p. 212-227, 2009. Disponível em: http://pepsic.bvsalud.org/pdf/pcp/v29n2/v29n2a02.pdf. Acesso em 22 de abril de 2020.

SILVA, A.A.M. Sobre a possibilidade de interrupção da epidemia pelo coronavírus (COVID-19) com base nas melhores evidências científicas disponíveis. Revista Brasileira de Epidemiologia, 
Rio de Janeiro, v. 23, 2020. Disponível em https://scielosp.org/pdf/rbepid/2020.v23/e200021/pt. Acesso em: 22 de abril de 2020.

WORLD HEALTH ORGANIZATION. Coronavirus disease (COVID-19) outbreak. Genebra: World Health Organization Press; 2020 Disponível em: https://www.who.int/emergencies/diseases/novel-coronavirus-2019. Acesso em 22 de abril de 2020 .

WORLD HEALTH ORGANIZATION. Report of the WHO-China Joint Mission on Coronavirus Disease 2019 (COVID-19). Genebra: World Health Organization Press, 2020. Disponível em: https://www.who.int/docs/default-source/coronaviruse/who-china-joint-mission-on-covid19-final-report.pdf. Acesso em 22 de abril de 2020.

ZHONGHUA; LIU; XING BIN; XUE ZA ZHI. An update on the epidemiological characteristics of novel coronavirus pneumonia (COVID-19). Chinese Journal of Epidemiology, Pequim, Vol. 41, n. 2, p.139-144, 2020. Disponível em: http://rs.yiigle.com/yufabiao/1181136.htm. Acesso em 23 de abril de 2020. 